\title{
APPLYING AN INDEX OF ADAPTIVE CAPACITY TO CLIMATE CHANGE IN NORTH-WESTERN VICTORIA, AUSTRALIA
}

Remy Sietchiping, Department of Primary Industries, PIRVIC

Correspondence to Remy Sietchiping: remy.sietchiping@dpi.vic.gov.au

or: rsietchiping@yahoo.com

Climate change calls for strategic planning that builds resilience in vulnerable areas to manage the associated risks. This paper discusses how adaptive various communities and industries are to climate change in the North West of Victoria (also known as the Victorian wheatbelt), Australia. Indicators of adaptive ability for communities and industries, and the importance of key drivers like government policies, expert advice and empirical evidence of developing this capacity are identified. It also incorporates input from key regional groups as well as current knowledge on adaptability of regional communities to climate change across three major themes: socio-cultural, economic, institutional/infrastructure. Each of these major themes has associated indicators, which in turn have an individual suite of measures, albeit all contributing to the overall adaptive capacity and spatial variability of these capacities. A Geographic Information System is used to collect and analyse the data and spatially represent the indicators and indices. Workshop participants' used their 'expert-judgment' to assess and weight indicators, measures and themes. The stakeholders' participatory assessment, the quantification of diversified data and interests and the importance of multiple policy outcomes make the findings locally relevant. We find that capacity and preparedness to adapt to climate change varies substantially across communities and different parts of the grains industry.

\section{INTRODUCTION}

For the last decade, the 'wheatbelt', which produces more than 95 per cent of grains in the Australian State of Victoria, has been undergoing a transformation largely due to prolonged severe drought conditions, social changes and declining terms of trade. This paper looks at how the grains industry and communities in the northwest (NW) of Victoria can better respond to these new challenges as well as the impact of climate change. A previous study, considering the impact of climate change on the Victorian grains industry, found the wheatbelt communities were highly vulnerable to climate change (Sposito et al. 2005b). To develop a strategic targeted response to climate change we ought to identify the adaptive capacity of communities to climate change and how this varies across the region.

The documented environmental, economic and social impacts of climate change imply some negative implications for Victorian grains production. Potential environmental impacts include an increased average annual temperature of $0.3^{\circ} \mathrm{C}$, a reduction of rainfall, frost days, increased evaporation rates, decreased run-off and aggravation of droughts, salinisation, wind and dust storms (due to landscape degradation and land clearing) and increased frequency of extremes climatic events (Penm et al. 2003; Sposito et al. 2005b; Diamond 2005). From a social perspective, there is an increased incidence of some health issues (e.g. depression, suicides, heat waves and cardiovascular or respiratory illnesses), continuous population decline in marginal rural areas, ageing population and issues around a community's connectivity, resilience and self-worth/esteem (Barr 2005). Economically, there is continuous loss of farm productivity, change in land suitab- 
ility for current agriculture commodities (mostly grains), and increased energy and transport costs (Kokic et al. 2005).

Findings from this research indicate that climate change can also bring opportunities, particularly to communities, industries and individuals that plan to act in anticipation of change. The impacts of climate change are spatially distributed and there is a growing body of knowledge that demonstrates that these impacts, risks and exposures will be both industry and region-specific (IPCC 2001; O’Brien et al. 2004; Nelson et al. 2005; Sposito et al. 2005b; Belliveau et al. 2006). Therefore, it is important when assessing 'adaptive capacity' to climate change to consider how it might vary across a region. Throughout this paper, adaptive capacity is defined as the ability of a system to adjust to climate-induced changes (including climate variability), by accommodating the associated risks or taking advantage of any opportunities. It includes the ability to implement planned adaptation measures, but excludes mitigation strategies.

Given that climate change adaptation will be played out at the local level this paper focuses on the propensity of communities active in the grains industry to be proactive and develop adaptation strategies (Tol 2005; Wilbanks 2005; Yamin et al. 2005). The paper starts with the premise that communities are central to the success of adaptation strategies. However, their efforts and long-term capacity should be supported by strong external adaptation measures and mitigation mechanisms (e.g. institutions, policies and incentives) to reduce climate change impacts (Yamin et al. 2005). Climate change is operating within the context of continuous regional adjustment and adaptation to the multiple stressors that are affecting individuals, society, economics, landscapes, policies, etc. (Belliveau et al. 2006; Reid and Vogel, 2006). Despite historic evidence of their capacity to adjust to various risks the impacts and magnitude of climate change remain a challenge for government, businesses and communities (Kokic et al. 2005; Nelson et al. 2005). This research shows the importance of involving interest groups, individuals and institutions when identifying climate change-related impacts and developing locally legitimate adaptation strategies, in order to ensure valuable, sound and informed policy and decision making (Klein et al. 2005; Adger et al. 2006; Naess et al. 2006).

As part of a research program conducted by the Department of Primary Industries (Victoria), 25 key stakeholders from three major groups (governance, farmer and industry) were interviewed to identify the current issues faced by the grains industry (to gauge their understanding of climate change), and consider their networks and communication strategies at play and who they think should take a leadership role in the climate change issue (Figure 1). For the purposes of this research, a stakeholder was considered an agency, organisation, group or individual who has a major interest in the grains industry in the North West region of Victoria, or who affects or is affected by the implementation or operation of the business.

Key issues that emerged from interviews include: a decline in terms of trade, community fragility, loss of productivity, drought, land suitability and soil degradation, and financial, institutional and infrastructure supports. These stressors were further refined and validated in two stakeholder workshops in which participants helped define and weight three major climate-related drivers and their indicators. Based on stakeholders input, empirical research and scientific evidence, the indicators identified were classified into three major themes: socio-cultural, economic, and institutional/infrastructure. 


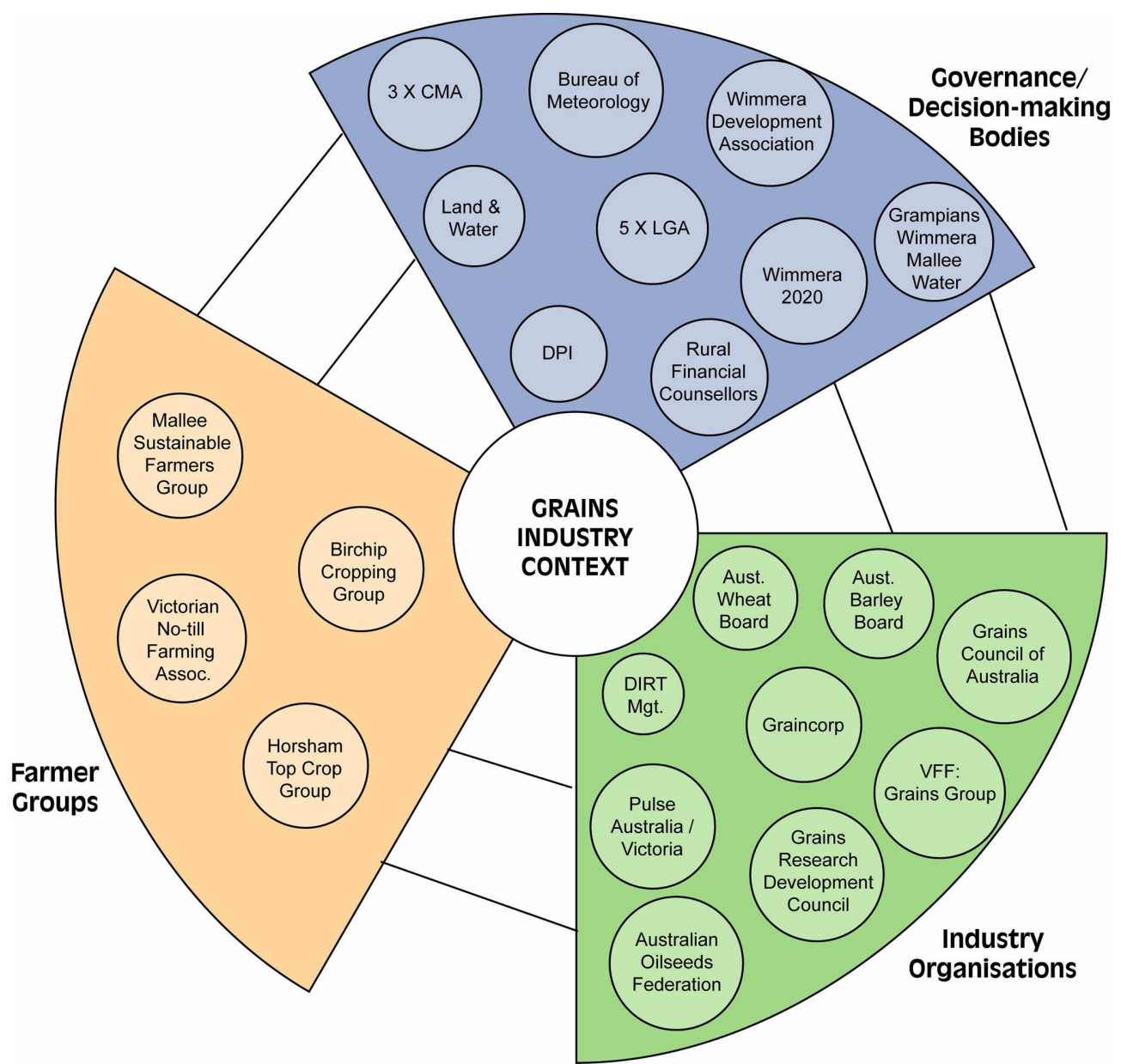

Figure 1 Grains Industry Stakeholders Interviewed and Engaged in the Climate Change Adaptive Capacity Project Participating stakeholders were put in three main groups: farmers, industry organisations, and governance or decision-making bodies

The paper is structured as follows. First, the study area is briefly presented. Second, the process of selecting relevant themes and their associated indicators is explained. Third, the modelling approach used to determine the adaptive capacity is presented. Finally, the results of the application in the NW of Victoria is presented and discussed.

\section{CLIMATE CHANGE AND THE VICTORIAN WHEATBELT}

Located in the North West of Victoria, Australia, the study area covers 43.5 per cent of the State and incorporates three catchment management authorities (CMAs) - Mallee, Wimmera and North Central (Figure 2), and 19 local government areas (Figure 3). The total population was approximately 337,000 in 2001 (ABS 2005), which was around seven per cent of the State's total population. 


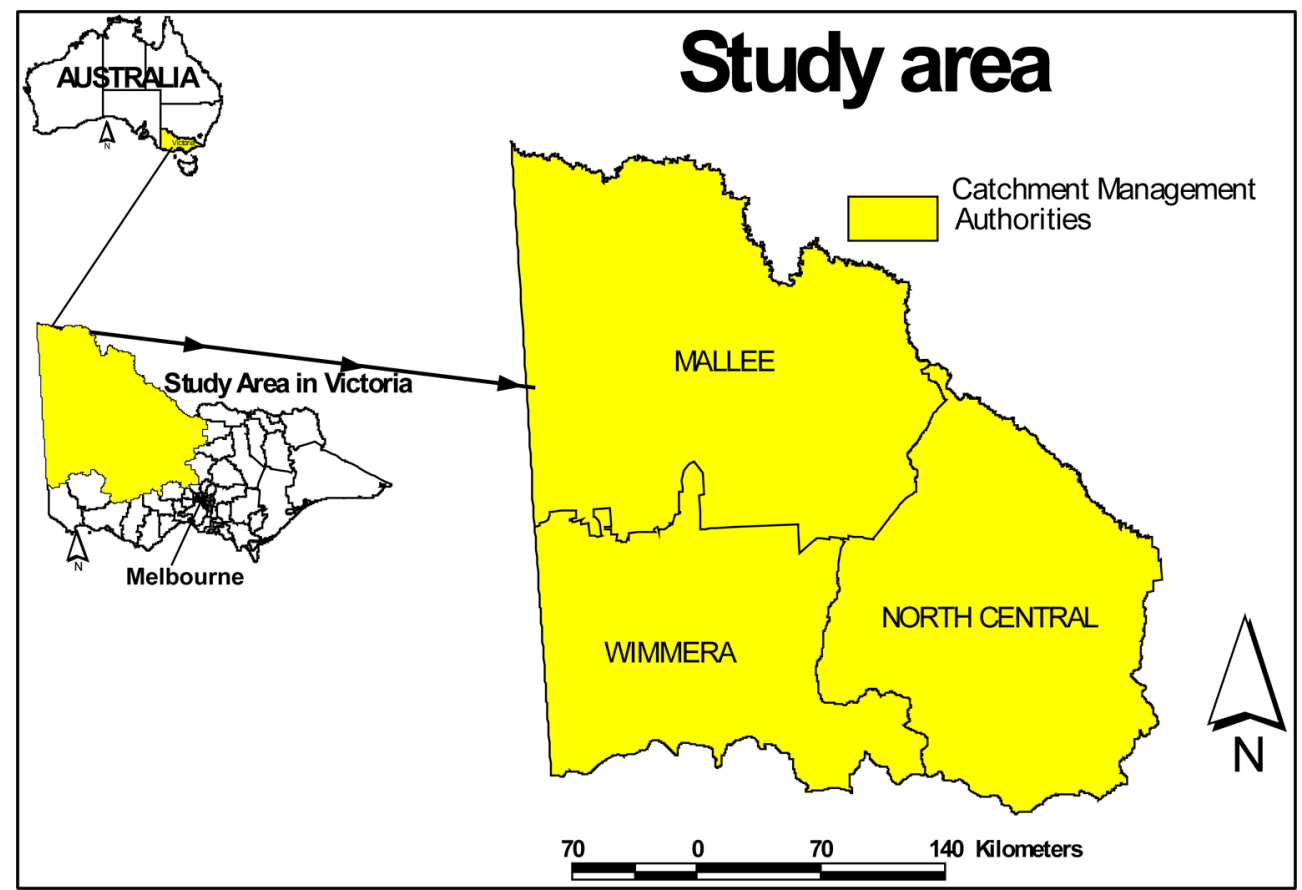

Figure 2 Study Area: Northwest Victoria in Australia

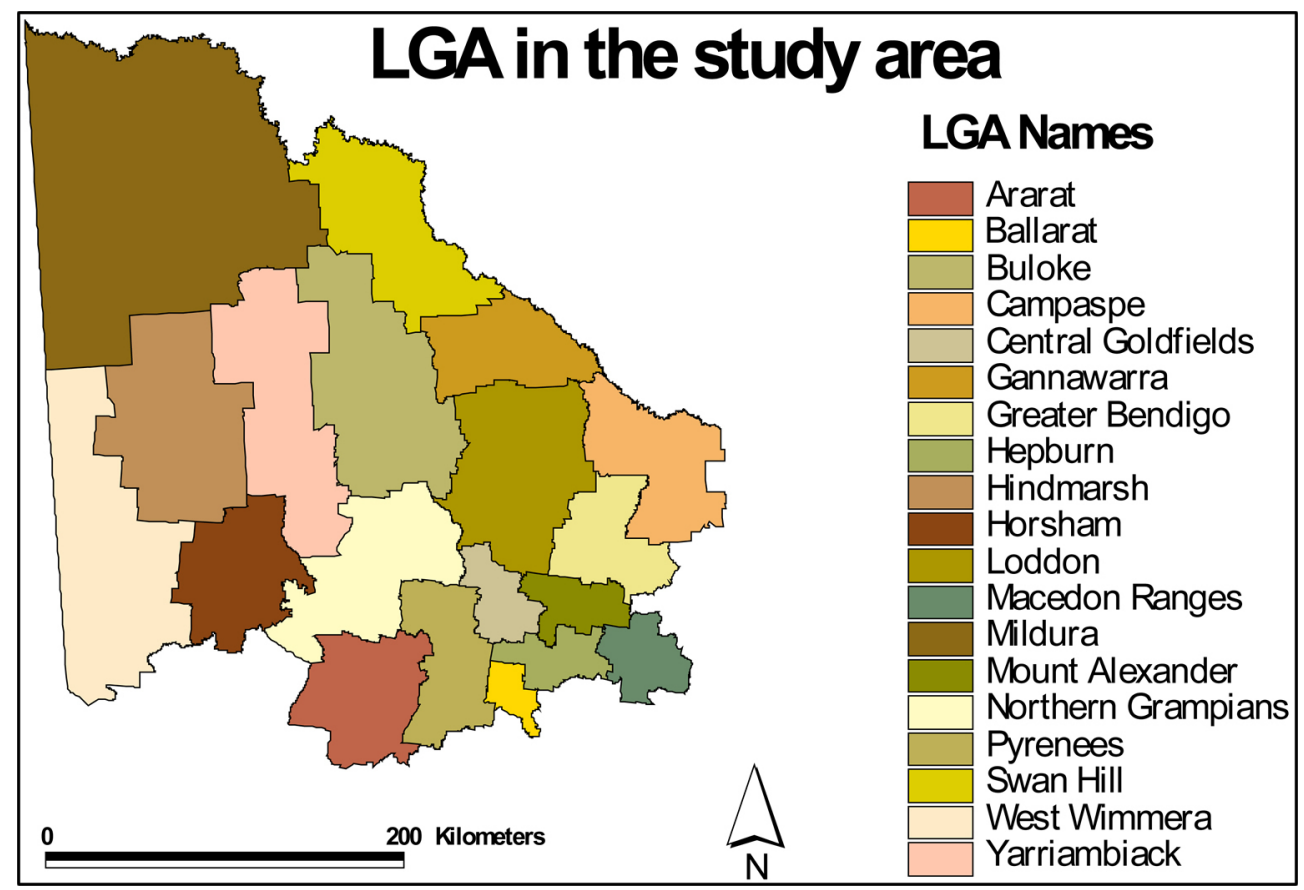

Figure 3 Local Government Areas (LGAs) Involved in the Project 
Agriculture production in the Northwest of the State is predominantly wheat and barley. For example, the region produces more than 93 per cent of the State's wheat. Figure 4 (a \& b) shows the value of production in Victoria for wheat and barley across the State. Sposito et al. (2005b) found that the grains industry in this region is one of the most vulnerable to climate change in Victoria as a result of prolonged drought and socio-economic decline.

Large scale human impacts on the landscape and environment started with the European settlement in the region around 1850, and were further reinforced by the Government's Soldier Settlement Scheme from 1920 (Diamond 2005). Native vegetation was cleared for dry-land agriculture and grazing. The low rainfall and persistent drought led to a significant investment by government in large-scale water infrastructure such as reservoirs, open channels and irrigation schemes. The region has experienced prolonged dry seasonal conditions leading to severe water shortages, exacerbated by the loss of up to 85 per cent of water from open channels through evaporation and seepage (GWMW 2005). Some of these stresses such as drought and land cover and use changes have led to acute manifestation of climate-related change.

As a consequence, the Victorian wheatbelt is under multiple stresses including prolonged dry seasonal conditions, remoteness, declining rural populations, decreasing terms of trade, a reduction of social services provision and an ageing population (Curtis and Byron 2002; Barr 2005; Penm et al. 2003).

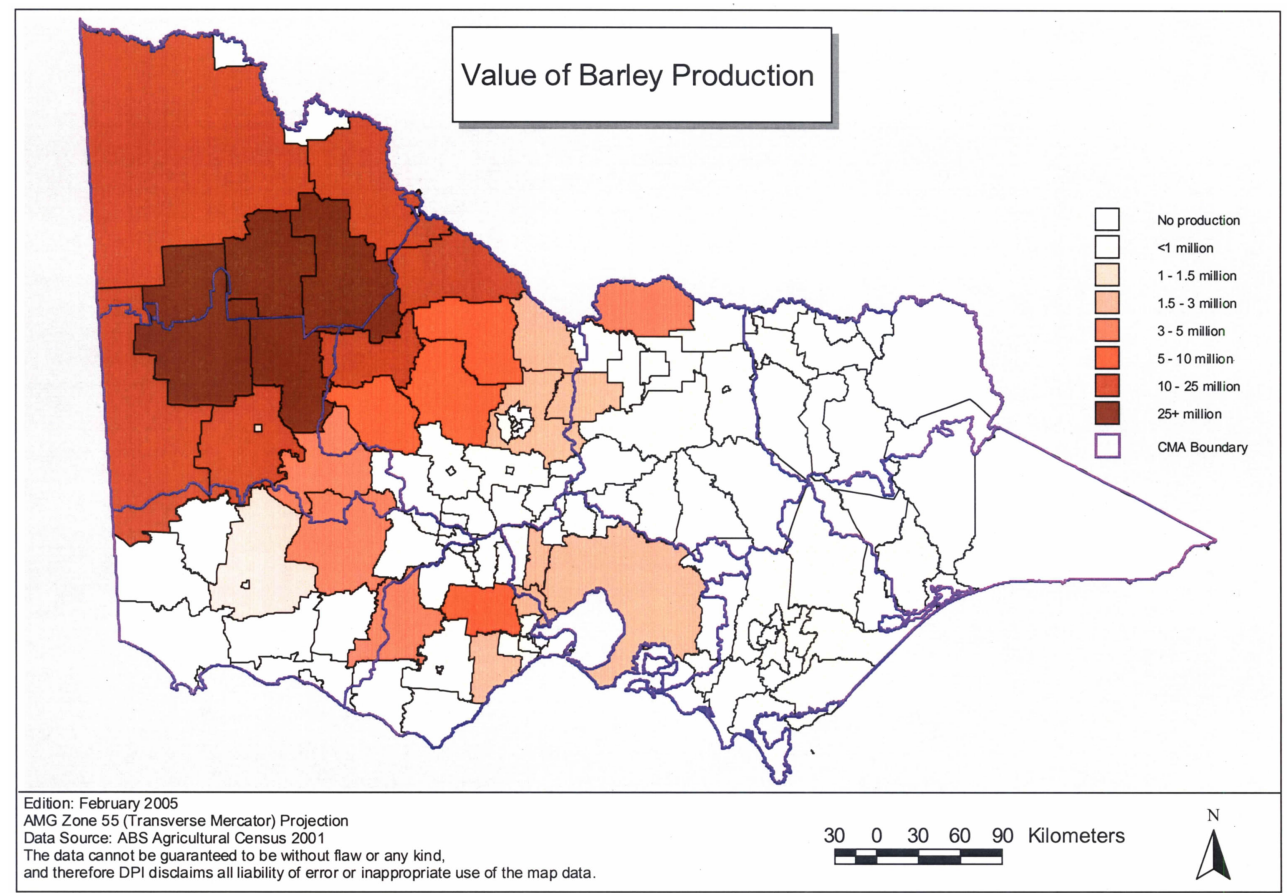

Figure 4a Value of Barley Production in Victoria

The agriculture production and value in the northwest of Victoria is predominantly wheat and barley. 


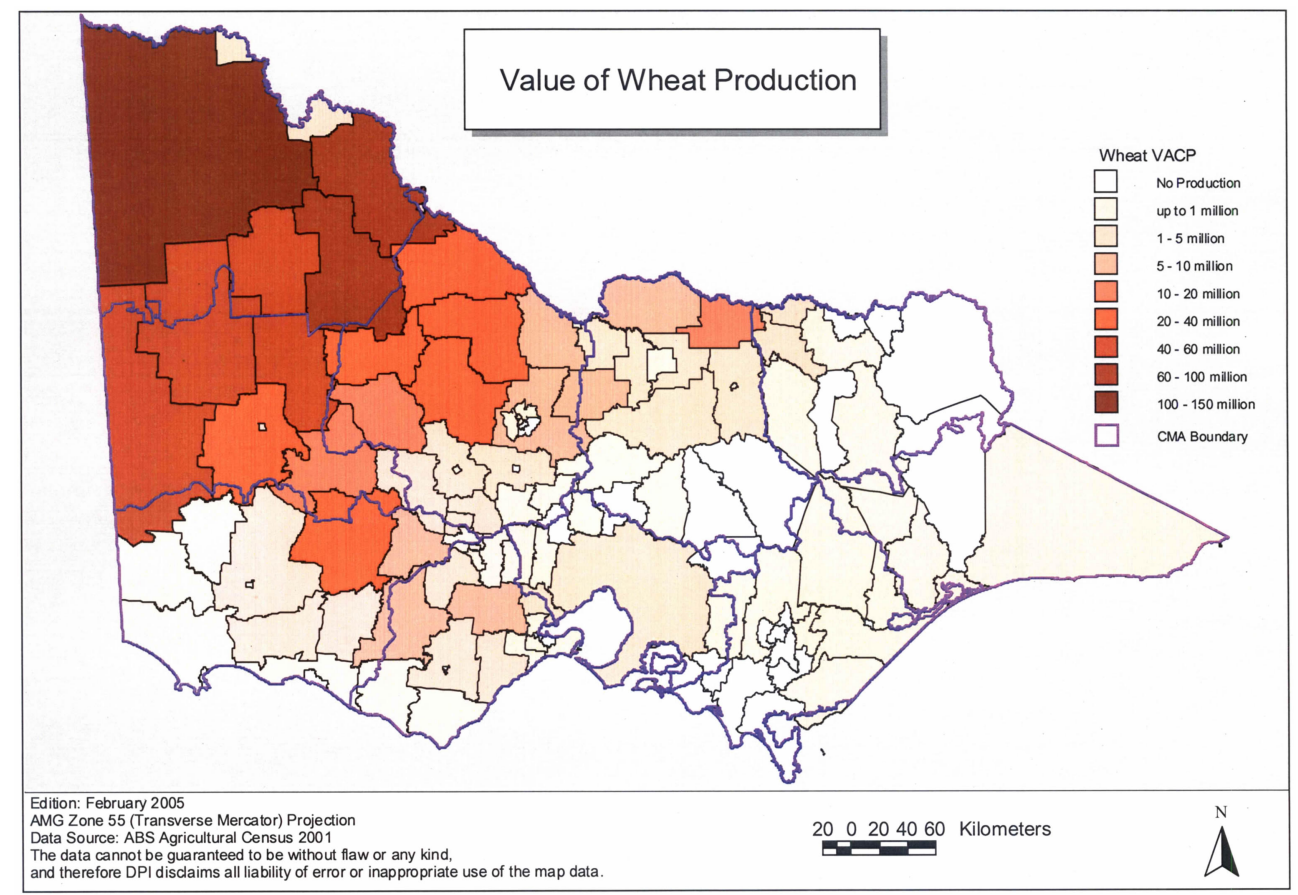

Figure 4b Value of Wheat Production in Victoria

The agriculture production and value in the northwest of Victoria is predominantly wheat and barley.

\section{DEVELOPING THE ADAPTIVE CAPACITY INDEX}

This section discusses suitable indicators for adaptive capacity in the Victorian wheatbelt. The selection of themes and indicators are drawn from the review of literature on climate change and adaptation (Sposito et al. 2005a), expert advice and stakeholders' input. This section discusses the process of selecting the indicators and themes, along with the underlying assumptions.

\subsection{SELECTING INDICATORS AND THEMES}

This research is based on the underlying assumption that indicators can be related to each other across a range of spatial and temporal scales. Indicators are conceived and selected with the understanding of the way in which they directly or indirectly relate to each other (facilitating, strengthening, hindering, etc.). The extent to which a single measure (e.g. education) could affect another (dependent or independent) measurement is extracted and accounted for through stakeholder assessment and the generic framework. It is, therefore, critical that all the indicators form an integrated and systematic part of the adaptive capacity of the industry as shown in Figure 5. 


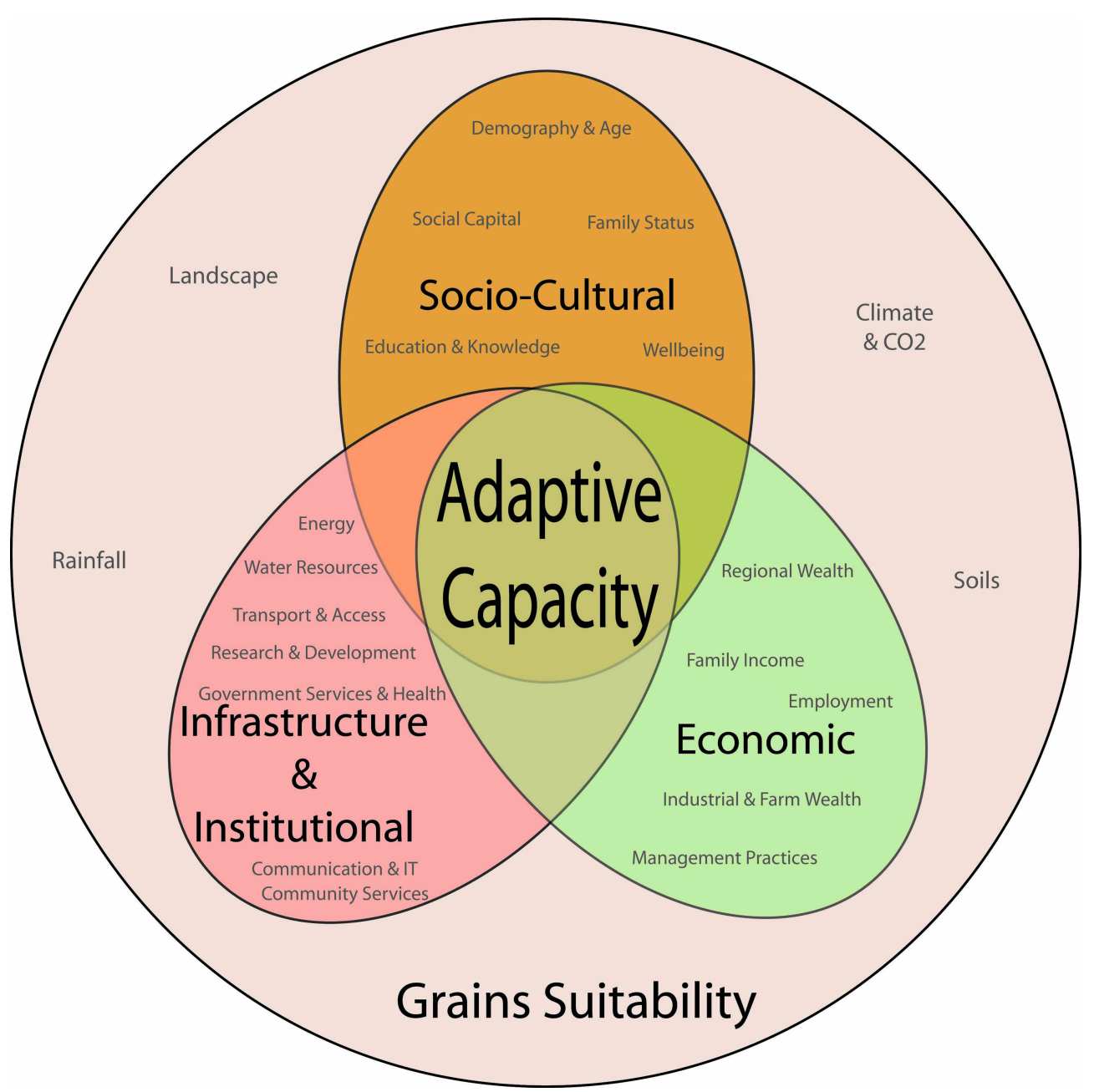

Figure 5 Components of the Adaptive Capacity Framework

The adaptive capacity is first the response to the region's changing suitability for grains production. The communities and industries adaptation to the changing suitability is then a function of three major themes: socio-cultural, economic and institutional/infrastructure. Each theme has a suite of indicators, which all contribute to the overall adaptability. All the themes, indicators and measures are informed by the climatic and biophysical conditions such as soils, climate and $\mathrm{CO2}$, landscape and rainfall.

It is worth noting that the adaptive capacity index is constructed from a multi-dimensional perspective that considers policy outcomes, structural adaptation, local context and stakeholder priorities. In so doing, the index recognises that adaptive capacity is a function of three broad themes crucial to a strong and prosperous grains industry and associated regional communities: socio-cultural, economic, institutional/infrastructure. These three themes are dependent upon the biophysical conditions for grains suitability. In the context of climate change and risk management strategies, each theme has a range of indicators and measures that highlight their relationship with the adaptive capacity of the grain industry (Innes 1994). All of these themes were later confirmed during stakeholder consultation. This adaptive capacity index approach also draws from the European application of Metzger (2005), which is spatially explicit and quantified. 
Our approach was informed by input from stakeholder consultation, as well as by expert advice and current scientific knowledge on climate change in the region (Sposito et al. 2005a).

Our research recognises that not only climate change as a global issue with important longterm considerations (e.g. mitigation strategies) and local adaptation options, but also acknowledges the influence of data availability, reliability and suitability to assess the adaptive capacity. Surrogates and proxies were used where key variables could not be fully or directly accounted for, due to data constraints (e.g. level of awareness of climate change) or measurement issues (e.g. leadership). A proxy indicator is an appropriate indicator that is used to represent a less easily measurable one. To further address such difficulties, this project draws on historical trends, reviews research and case studies, and engages stakeholders in the region to screen sets of relevant indicators. The final indicators were selected based on criteria such as efficiency, reliability and availability.

The selection process employed four main criteria: scope, relevance, availability and interest (Innes 1994). The set of indicators were first scoped to ensure there were no key ones missing and that they were sensitive and 'fitted' stakeholder perceptions, community concerns and scientific investigations. Indicators were then assessed to determine how they relate to the adaptive capacity of the grains industry and their sensitivity against the expected adaptive capacity outcomes. The broad suite of indicators were familiar to stakeholders and policy makers, so the results provide a platform to advocate further change in policy orientation and community actions (Tompkins and Adger 2005). Finally, the availability of indicators to be used was assessed.

A suitable set of measures was then identified to evaluate each indicator. The following questions guided the potential measures of each indicator:

- Is there any relation (positive or negative) between the measure and the adaptive capacity to climate change?

- Is the measure the most relevant and pertinent in representing the indicator under consideration?

- Why is this measure particularly important for the sustainable progress of the region?

- What are the key facets of progress in the measure that any headline indicator/measure should seek to express?'

The final indicators were then sorted into three major themes: economic, socio-cultural, and institutional/infrastructure. Figure 6 shows the overall adaptive capacity framework applied in this research.

\subsection{INDICATORS AND ASSUMPTIONS}

Indicators were selected based on a suite of assumptions, particularly their influence on adaptive capacity and stakeholder inputs. The adaptive capacity is informed by the wheat and barley suitability models based on three major indicators: soil, climate and topography (Agriculture Victoria Services 2002). Whereas the assumptions for the biophysical suitability for wheat and barley resulted from expert judgement (i.e. selected wheat and barley experts and scientists), the adaptive capacity assumptions and indicators were based on stakeholders input. The assumptions are presented below within three key themes. 


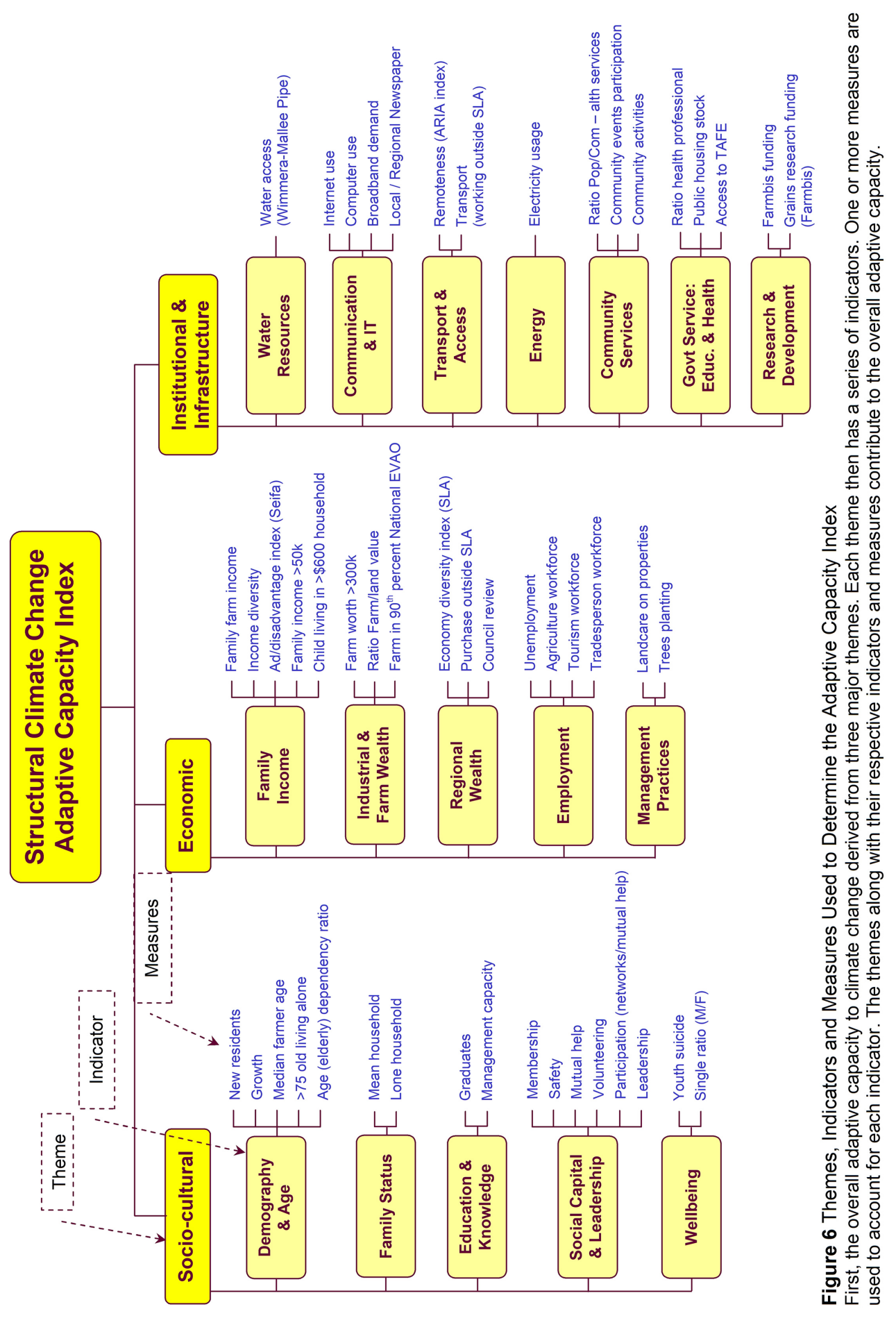




\subsubsection{SOCIO-CULTURAL ASSUMPTIONS AND INDICATORS}

The ability of social systems to adapt depends on social capital, population sustainability, family status, educated and knowledgeable inhabitants (Curtis and Byron 2002; Adger 2003; DVC 2005; Ford et al. 2006). A population decline in a region has negative impacts on its social services, social capital and networks (Allen et al. 2001; Barr 2005). Based on our research and participants input, a region with high social adaptive capacity was assumed to have:

- a thriving population that attracts new residents and increases its population densities;

- a supportive family setting with fewer lonely households and a 'sustainable' number of people per household (>2.5);

- a decline in the average age of the population (farmers) with lower dependency ratio;

- an educated and knowledgeable population, especially with a higher graduate ratio and management skills;

- strong social capital, with high levels of community participation, safety, mutual help, networks, leadership, volunteering and a sense of security;

- a greater level of understanding of climate change-related threats; and

- a good standard of human wellbeing (e.g. low youth suicide and singles ratio).

\subsubsection{ECONOMIC ASSUMPTIONS INDICATORS}

Economic conditions are important to build the resilience of communities and industries to climate change (Barr 2005; Howden and Crimp 2005; Ludwid and Asseng 2005). Participants in the project identified the economic impacts as 'less money in the pocket', declining terms of trade and reduced employment opportunities. The participants at the workshops highlighted economic pointers to developing adaptive capacity. For the selection of indicators, it was assumed that an adaptable economy will demonstrate high:

- personal wealth to 'ride out' bad years with poor returns. Also, the population in the region should earn a wage/income to ensure that standards of living can be maintained;

- family income (above \$A50,000 per annum) and a diversity of income sources including offfarm income. Off-farm income is the sum of earnings outside the farm products and therefore includes wages off-farm, other business income, investment and social welfare (Martin et al. 2005);

- industry growth (a long-term economic perspective) and a willingness to invest in the future of the industry. Also there should be a greater farm value (farm worth) and continuous increase in agricultural operations, whilst securing higher returns;

- market performance and stable returns to ensure a reasonable level of certainty for producers; and

- regional wealth to support and attract investment and a skilled workforce through council revenue, higher farm entry and increased cooperative farming.

\subsubsection{INSTITUTIONS/INFRASTRUCTURE ASSUMPTIONS AND INDICATORS}

Institutions and infrastructure are important in estimating the communities' resilience or vulnerability to climate change (Agrawal 2002). For instance, a Norwegian study showed the presence of an environmental officer in local government as an indicator of a community's ability to address 
environmental issues (Naess et al. 2006). For this research indicators were identified through participants' input during interviews and stakeholder workshops. Therefore, the institutional/infrastructure capacity of a location to adapt to climate change was considered to be based on having:

- a strategic location that will secure sufficient and available water supply and efficient management (e.g. water pipeline);

- reasonable access to communication and information infrastructure and institutions for learning exchange (e.g. internet);

- secure access to transport facilities and infrastructure (e.g. adequate road and railway systems for the transport of goods and services);

- access to a range of innovative technological options (e.g. new cultivars);

- access to and availability of support services (e.g. health infrastructure, institutions; environmental officers); and

- an appropriate environment for leadership development and participation (e.g. landcare group participation and residents sitting on committees/boards).

Research shows that the number of final indicators used to develop indices of adaptive capacity varies widely across case studies. For example, a vulnerability index developed for broadacre agriculture in Australia used 12 indicators grouped within five major themes (Nelson et al. 2005): human (education, management capacity), social (partnership in the business, internet usage, landcare membership), natural (land degradation index, Pasture Growth Index), physical (diversity of income, area operated) and financial (average income, income risk, off-farm income). In another case, Bhadwal et al. (2003) used 11 indicators to develop an adaptive and vulnerability index in rural India, while Brooks et al. (2005) used up to 45 indicators to compare countries' adaptive and vulnerability indices across Europe. In all these cases, the research objectives, experts' advice, and participating stakeholders' inputs guided indicator selection. A common feature of the case studies is the allocation of equal weights to the indicators and themes. This study however, argues that not all indicators equally contribute to the assessment of adaptive capacity. As will be shown in more detail below, stakeholders were involved in both selection and weighting of indicators and themes.

\section{METHODOLOGY}

A range of methods could be used to develop climate change adaptive capacity indices. The objectives of the research often decide which methods to use. For instance, when the importance to explore, compare and statistically explain the consistency and variation amongst indicator sets was paramount, some climate change studies used factor analysis techniques (O'Connor et al. 1999; Lazo et al. 2000). The bayesian probability could be used to explore belief thinking on climate change (Karl et al. 1996) and could be a useful tool for analysing uncertainties (Hobbs 1997). Analytic Hierarchy Process, a multi-criteria evaluation method (Saaty and Vargas 2001), and Bayesian probability could both be used to weight community's preferences. However in this research we have used a communities' self-assessment approach for defining their capacity to adapt to climate change. This approach uses a combination of stakeholder engagement and GIS techniques to develop an adaptive capacity index to climate change. Further study may be 
required to explore and explain the consistency and variation amongst ACI indicator sets as well as examine the relationship between groups involved in the project. Sections below explain the adaptive capacity index and how stakeholders were engaged.

\subsection{ADAPTIVE CAPACITY INDEX}

The development of the following adaptive capacity index (ACI) used criteria weighting. For this particular application, the overall adaptive capacity index (ACI) is expressed in equation 1 :

(1.) $\quad A C I=\left(S . S_{w}\right)+\left(E \cdot E_{w}\right)+\left(I n \cdot I n_{w}\right)$

where $A C I$ is the overall Adaptive Capacity Index (scale of 0-10);

$S$ is the socio-cultural score,

$S_{w}$ is the socio-cultural weighting,

$E$ is the economic score,

$E_{w}$ is the economic weighting,

In is the institution/infrastructure score,

$I n_{w}$ is the institution/infrastructure weighting

Stakeholders defined the weighting for each theme.

The adaptive capacity index was also calculated for each of the three themes. For example, the socio-cultural adaptive capacity was obtained as in equation 2 :

(2.) $S_{w}=\left(\operatorname{Ind}_{1}\right)+(\operatorname{Ind} 2)+\ldots+\left(\operatorname{Ind}_{n}\right)$

where Ind is the weighting of all $n$ measures for an indicator.

Again, stakeholders defined the weighting for each indicator.

Each indicator could have one or more measures. Equation 3 was used to derive the weighting for each indicator:

(3.) $\quad$ Ind $_{1}=\left(M_{1}\right)+(M 2)+\ldots\left(M_{n}\right)$

where $M$ is the weighting for a measure of an indicator; all measures on an indicator are equal.

\subsection{VALUING STAKEHOLDER INPUTS}

Studies show that stakeholder participation has the advantage of nurturing consensus, transparency and dialogue between scientists and stakeholders (Kundzewicz et al. 2002; Alberini et al. 2006), and informing grassroots perception and actions in adaptation strategies (The Economist 2003). This is important given previous studies have shown that adaptation responses are often taken at the local level (Welp et al. 2006).

Inputs into this research utilised three stages of stakeholder engagement: a series of interviews, followed by two workshops. In particular, 25 key individuals and institutions, selected on the basis of their stake in the grains industries in the region, were interviewed. Participants fell within three broad categories: governance, grain industry and farmer groups. The distribution of participating stakeholders is shown on Figure 1. Their responses then helped identify possible indicators relevant to the region and the grains industry. The interview process revealed through 
stakeholders' accounts, their attitude, perception and understanding of climate-related issues, impacts, networks and leadership.

In the second stage, participants were shown models of climate change impacts on wheat and barley suitability. Based on changes in crop suitability, participants were first asked to identify the potential impacts of climate change at two levels: farm gate and flow-on effects for the community. Participants identified possible adaptation strategies and actions. The results of the first workshop were then incorporated into the selection process of possible indicators and measures. These indicators and measures were then used to map an adaptive capacity index for the region.

The second workshop aimed at validating the adaptive capacity index approach and the preselected indicators. To achieve this aim, a sample output of the adaptive capacity index was presented along with the process of indicator selection and weighting. Participants were then given a list of possible indicators for each theme (socio-cultural, economic, and institutional/infrastructure). The following five steps were executed:

- Participants were asked to respond to the assumptions for each theme and indicator in relation to adaptation of the region and industry to climate change.

- Agreement was sought on the choice of the indicator, which implied that, some new indicators and measures were added, some were removed and others were reorganised or moved to other themes. For instance, participants added the following indicators: research and development, health services, energy, and community services. Some indicators or measures were reassigned in other categories. For instance, leadership was moved from management practices to social capital; an age indicator was merged with demography, technology access was merged with communication (to become communication and IT).

- Participants were then asked to weight on a scale of 0 to 100 indicators within each of the three themes.

- Scores from all participants were recorded on a spreadsheet and averaged.

- The same procedure was followed to derive the score for each theme, which was then used to create the ACI (Table 1) and map the spatial variation of adaptive capacity in the region.

It is worth noting that despite differences of opinion as to the importance of the themes and indicators, some general trends were observed. In the case of the themes, for example, (Figure 7) participants consistently rated socio-cultural and economic factors as more important than those considered in the institutional/infrastructure theme.

If considerable differences appeared in the selection or the scoring of indicators or measures, discussions were held to ensure that a group consensus was met. Therefore, the models presented below reflect stakeholders' contribution to and validation of the indices. The scores obtained were then used to model various adaptive capacity indices using the Model Builder function in ArcView GIS. In particular, the weighted overlay function used stakeholders' scores (Table 1). Adaptive capacity indices were derived for socio-cultural (Figure 8a), economic (Figure 8b) and institutional/infrastructure (Figure 8c). The overall adaptive capacity index (Figure 8d) was obtained using the same approach. 


\begin{tabular}{|c|c|c|c|}
\hline Themes & Weight/100 & Indicators & Weight/100 \\
\hline \multirow{6}{*}{ Socio-cultural } & \multirow{6}{*}{34} & Demography and Age & 16 \\
\hline & & Family status & 14 \\
\hline & & Education and Knowledge & 22 \\
\hline & & Social Capital and Leadership & 27 \\
\hline & & Wellbeing & 21 \\
\hline & & Total & 100 \\
\hline \multirow{8}{*}{$\begin{array}{l}\text { Institution and } \\
\text { Infrastructure }\end{array}$} & \multirow{8}{*}{28} & Water & 19 \\
\hline & & Communication and IT & 17 \\
\hline & & Transport and Access & 14 \\
\hline & & Energy & 9 \\
\hline & & Community Services & 14 \\
\hline & & Government services & 15 \\
\hline & & Research and Development & 12 \\
\hline & & Total & 100 \\
\hline \multirow{6}{*}{ Economic } & \multirow{6}{*}{38} & Family Income & 19 \\
\hline & & Industry and Farm wealth & 21 \\
\hline & & Regional wealth & 19 \\
\hline & & Employment & 16 \\
\hline & & Management practices & 25 \\
\hline & & Total & 100 \\
\hline
\end{tabular}

Table 1 Weights of Themes and Indicators

(as obtained by averaging the weightings from each participant at the stakeholder workshop held in Horsham, Australia on June 20th, 2006)

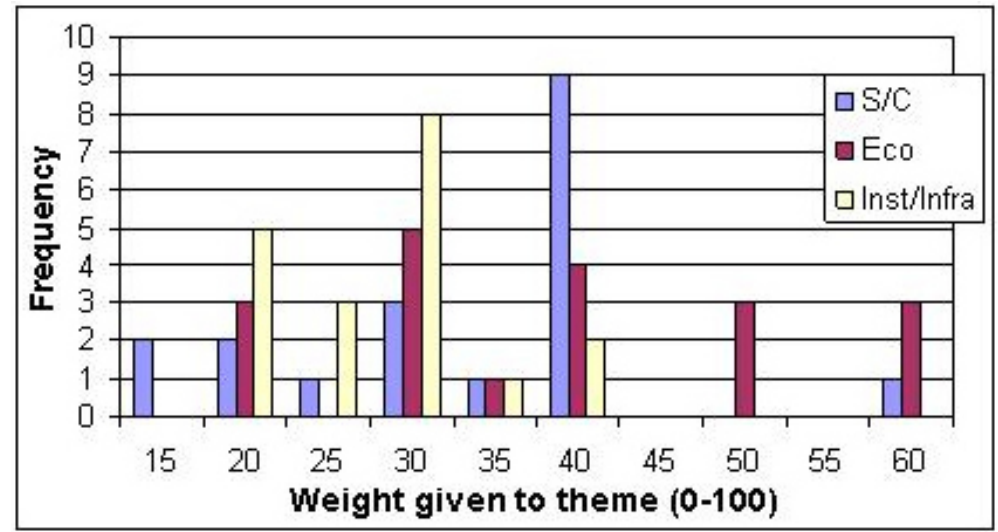

Figure 7 Frequency of Weightings by Participants at Adaptive Capacity Index Workshop 


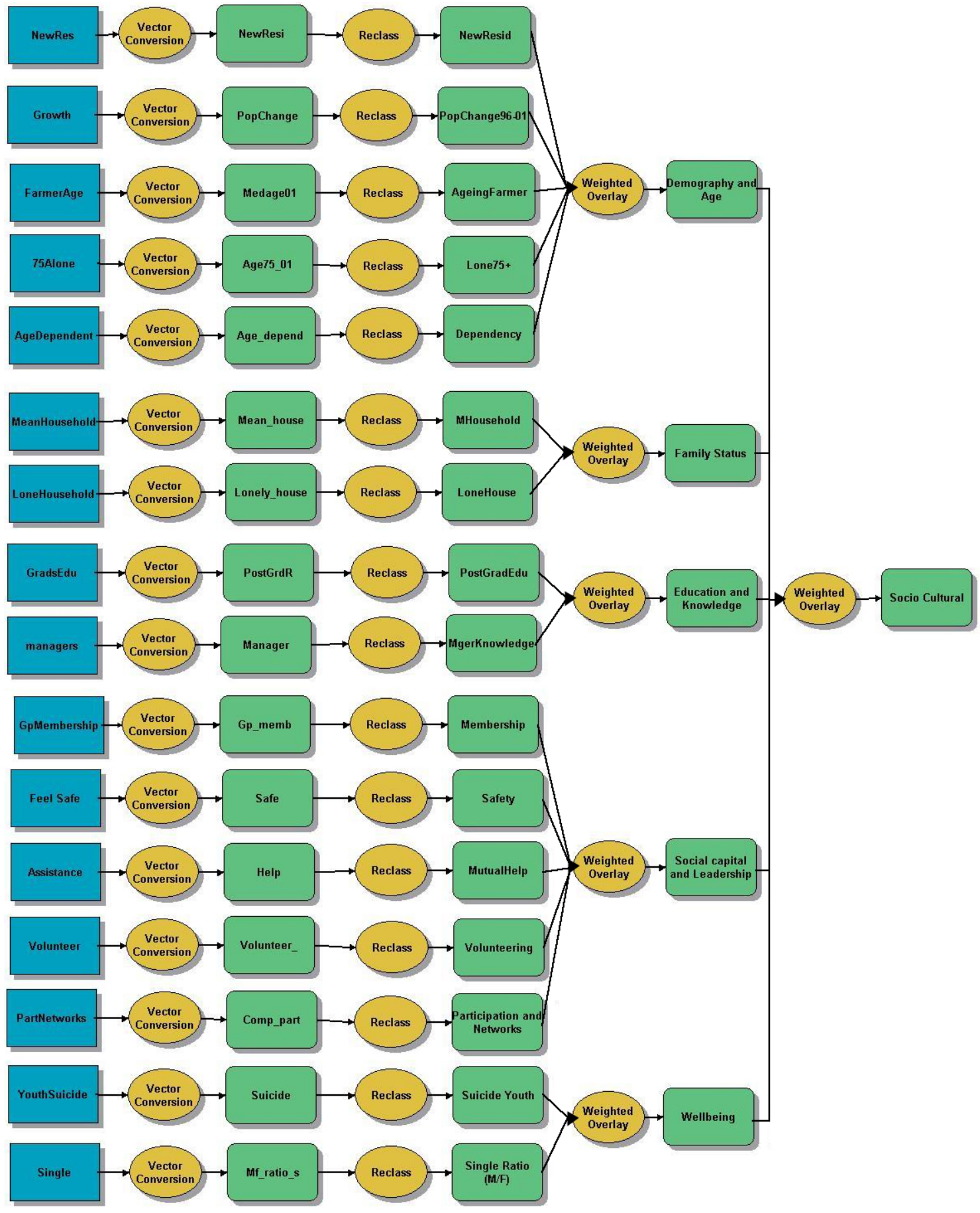

Figure 8a Socio-Cultural ACI Model 


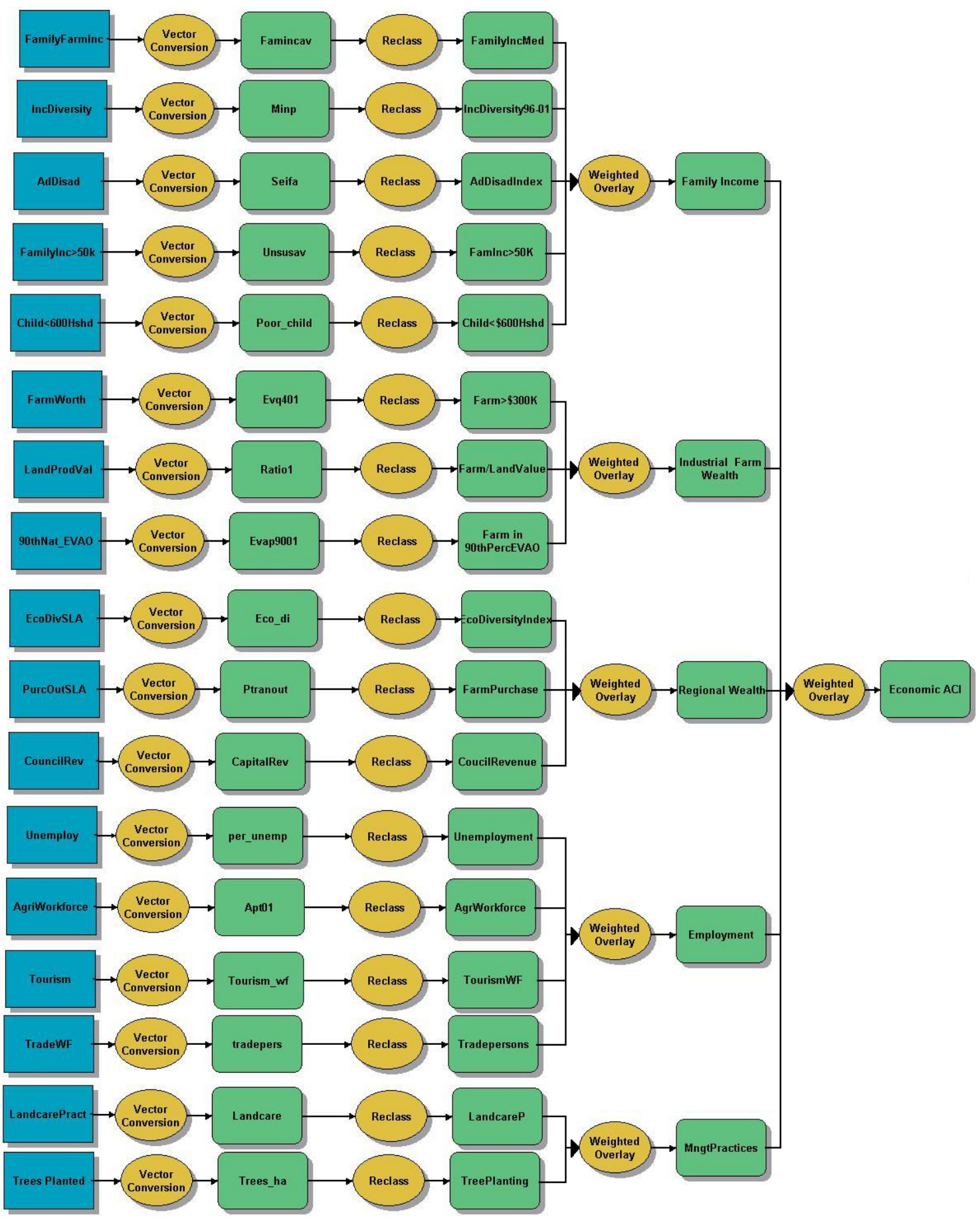

Figure8b Economic ACI Model 


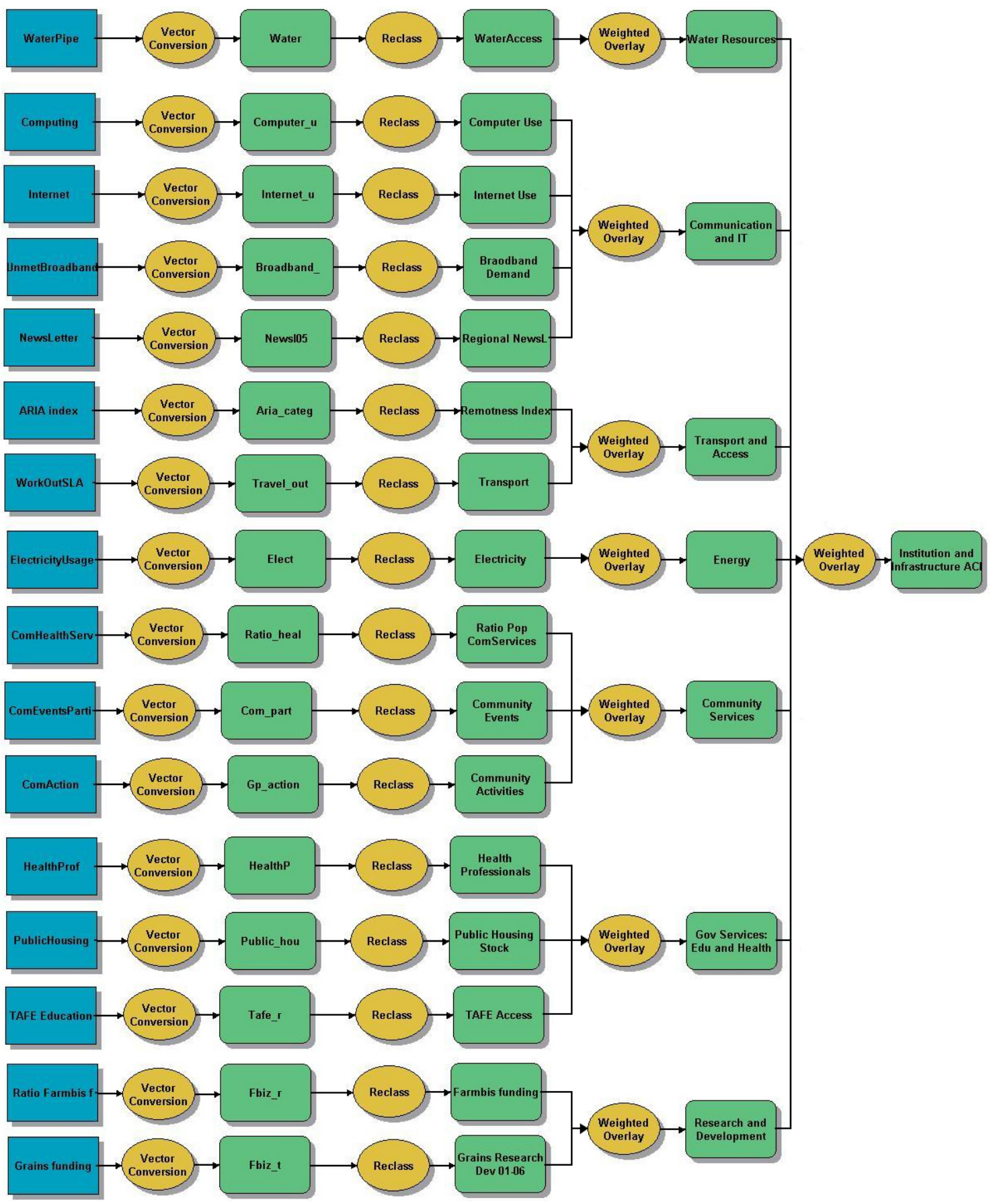

Figure8c Institutional/Infrastructure ACl Model 


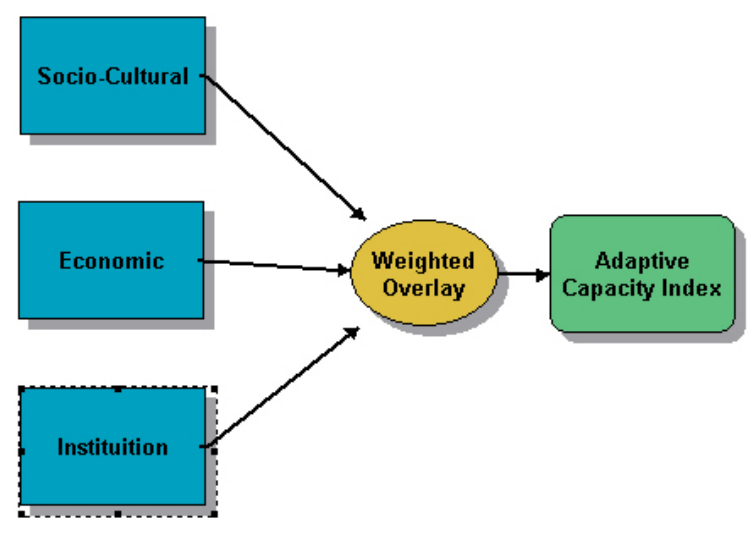

Figure8d Overall $\mathrm{ACl}$ to Climate Change Model Climate change: Building Adaptive Capacity Indices (ACI) models

The models produced adaptive capacity indices for each of the variables considered. Indices are then used to spatially map the adaptive capacity of the region ranking from lowest to highest.

\section{RESULTS}

Figures $9 \mathrm{a}, \mathbf{9 b}, \mathbf{9 c}$ and $9 \mathrm{~d}$ show some outputs from the adaptive capacity index. The results indicate each area's capacity to adapt to the projected moderate climate change scenario. The overall adaptive capacity score could hide some spatial discrepancies across the region. For example, areas that demonstrate high social adaptation did not necessarily score high on other themes such as economic, institution/infrastructure. Such spatial differentiation has two explanations: the choice of indicators and the weighting. Overall, the wheatbelt region recorded high social capital and resilience scores despite its eroding social services and infrastructure. However, the most important factor that has strengthened and validated the adaptive capacity index is the stakeholder engagement process.

Adaptive capacity indices were calculated for each theme, indicator and measure from which the overall adaptive capacity index was derived.

The results indicate a community's adaptive capacity and preparedness for climate-induced change varies across the region. Furthermore, mapping adaptive indicators helps to highlight communities and industry strengths in coping with changes as well as areas for improvement. Adaptive strategies varied between the stakeholder groups, which included individual farmers, farmer groups, community groups, industry organisations, and governance agencies. During the interviews, we noted that:

- Farmers and Farmer groups were more inclined to adopt sustainable practices, managerial and behavioural changes.

- Community groups focused on resilience factors and networks.

- Grains industry groups focused on the economic returns.

- Governance bodies were concerned with institutions and their supporting infrastructure. 


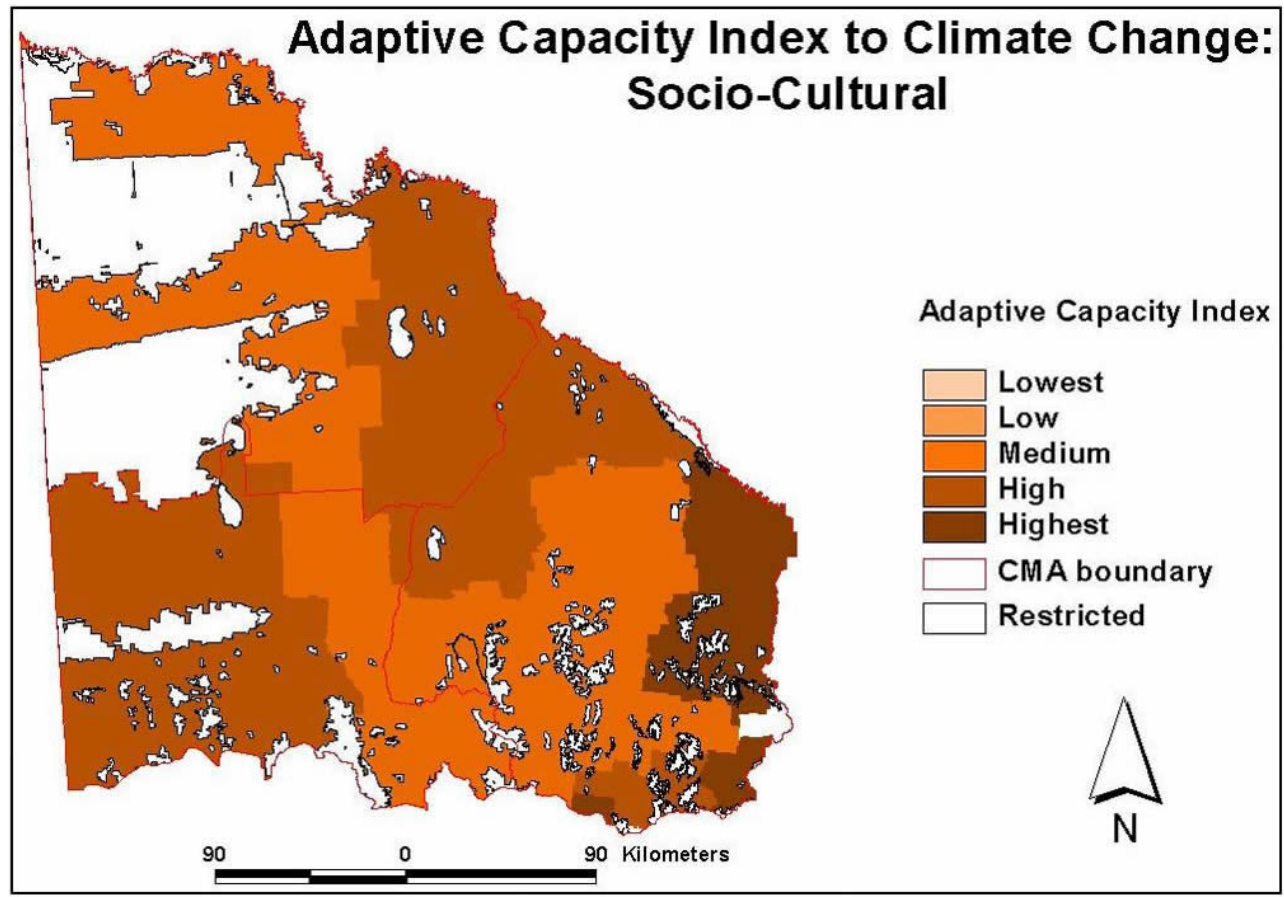

Figure 9a Spatial variation of Socio-cultural ACl to Climate Change in NW Victoria

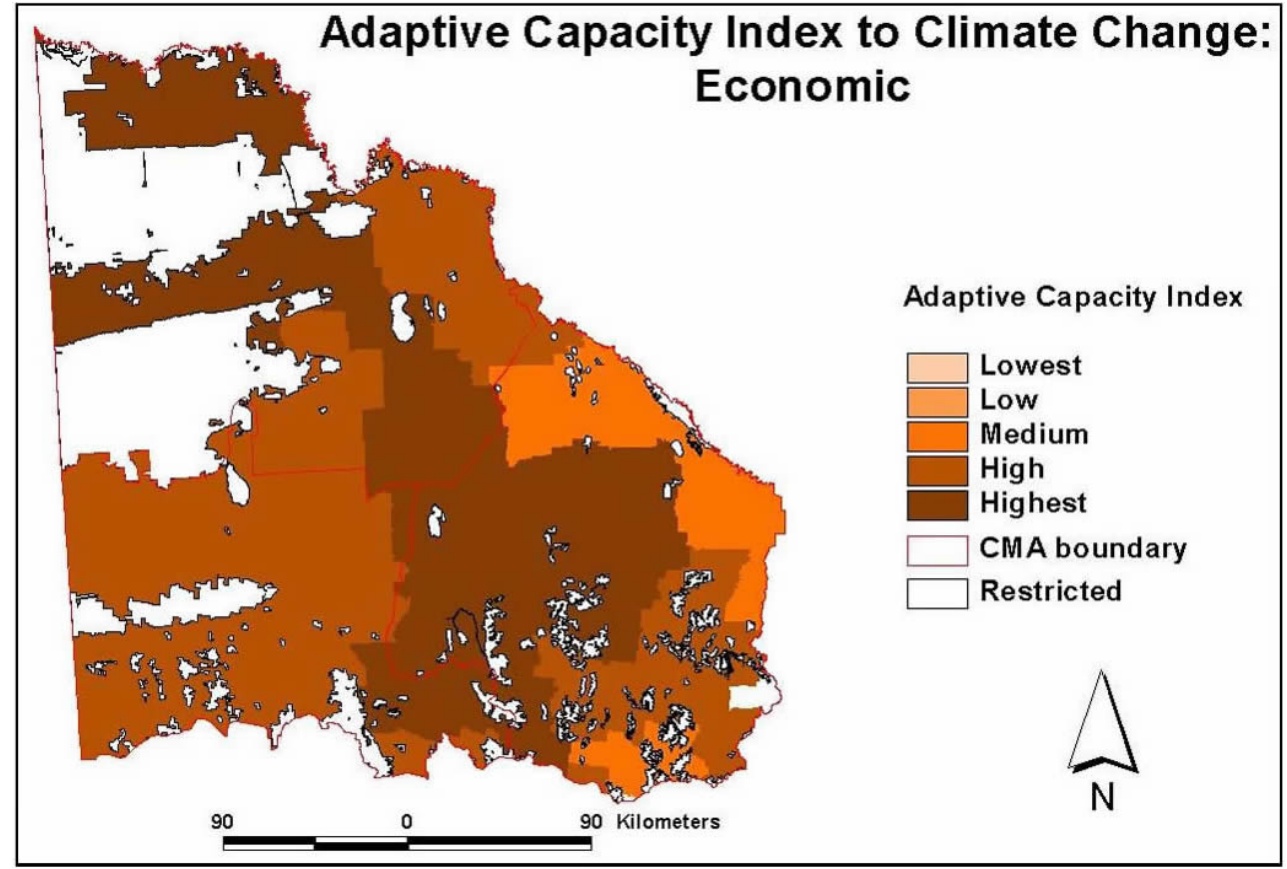

Figure 9b Spatial variation of Economic ACl to Climate Change in NW Victoria 


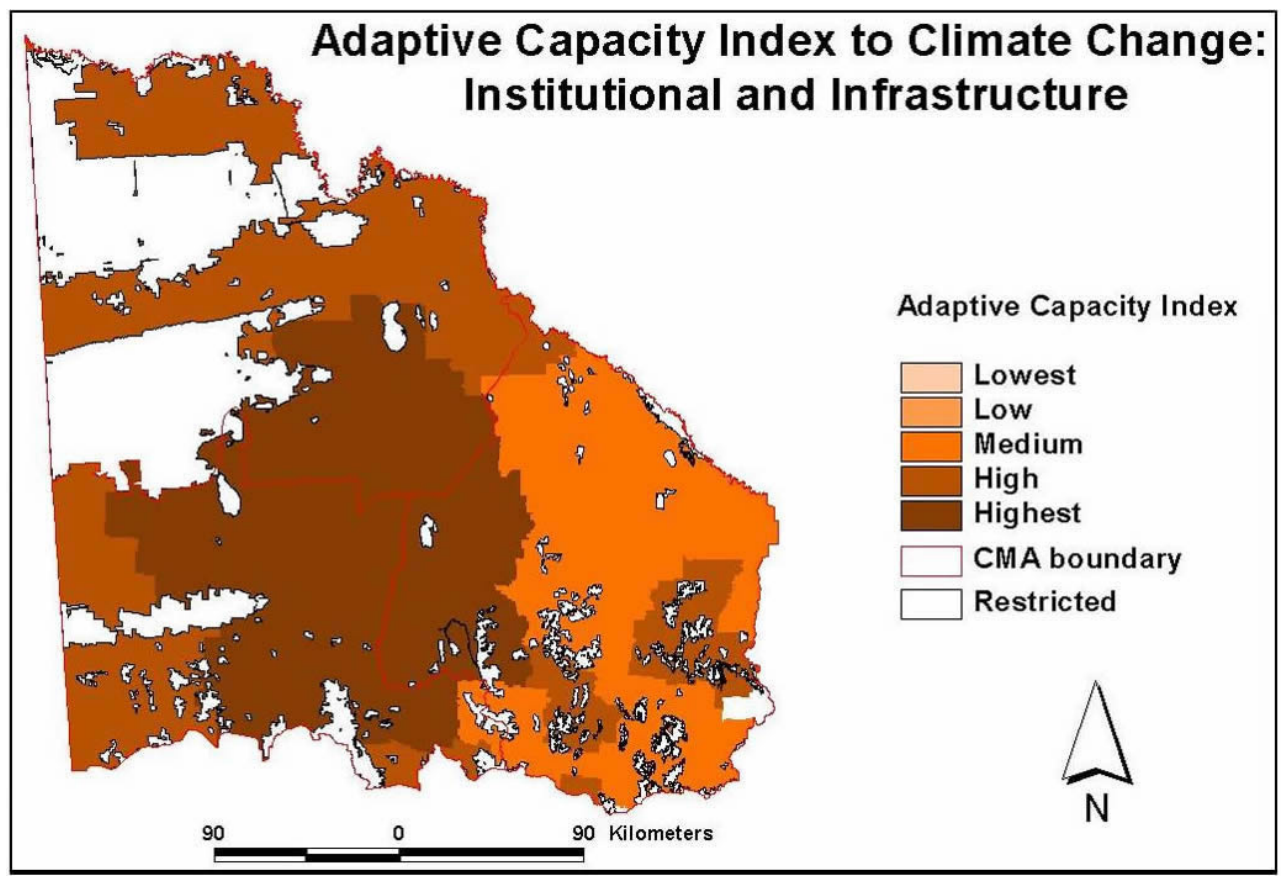

Figure 9c Spatial variation of Institution/Infrastructure ACI to Climate Change in NW Victoria

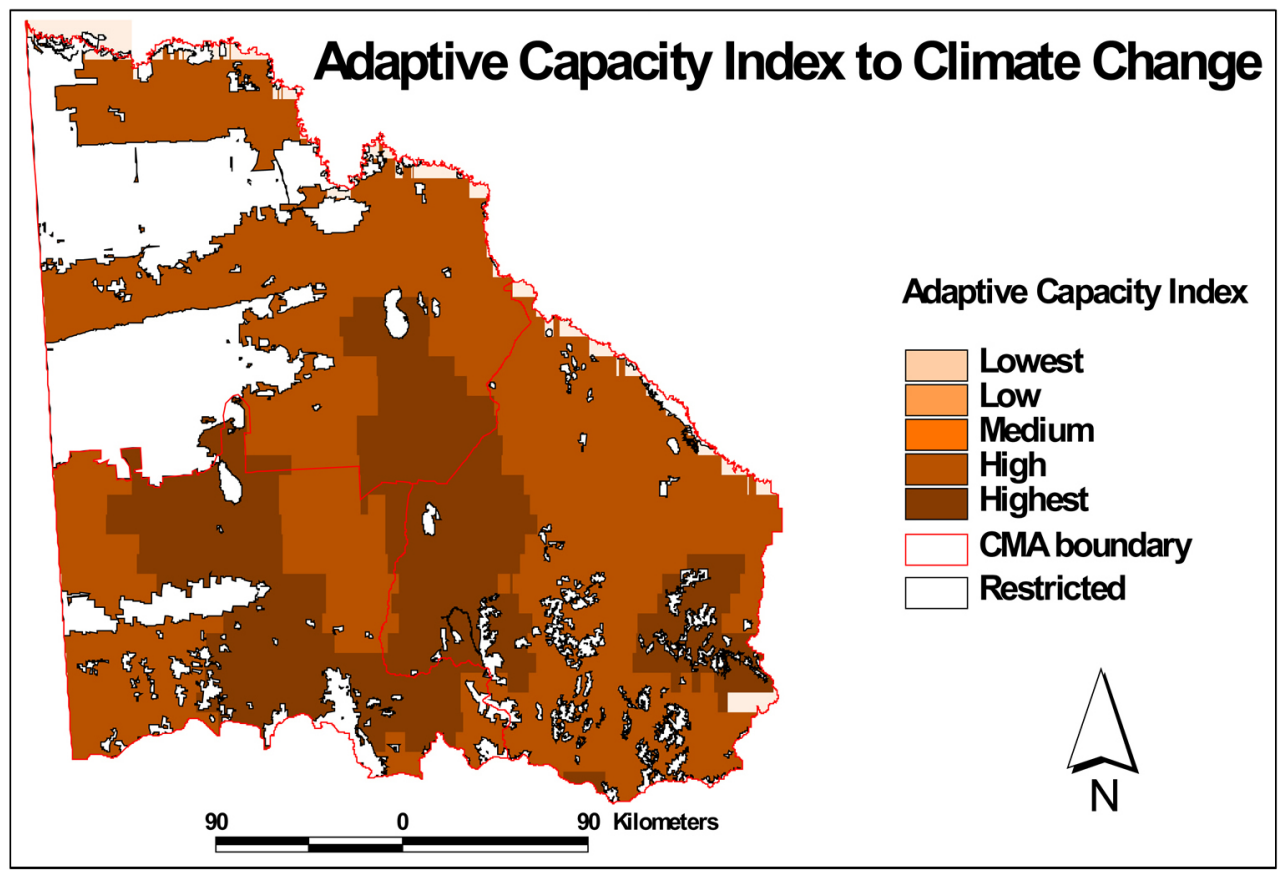

Figure 9d Spatial variation of Overall adaptive capacity index to climate change in NW Victoria

Mapping the Adaptive Capacity: Socio-cultural, Economic and Institutional/Infrastructure Indices, and the Overall Index 


\section{DISCUSSION}

The ability of communities and industries to adapt to climate change varied depending on factors such as access to resources, institutional/infrastructure support, community strength, availability of locally relevant scientific outputs and technology.

\subsection{SHORT-TERM AND LOCAL ADAPTATION STRATEGIES}

Climate-related changes will create opportunities and 'winners', especially for proactive industries, communities and entrepreneurs (O’Brien and Leichenko 2003). Climate change may also exacerbate the existing vulnerability of some farmers and communities. Small scale grain farms are particularly vulnerable and are likely to be squeezed by the current trends like farm consolidation, declining terms of trade (about 3.1 per cent per year below the 1990s level), high farm exit and lower entry rates (Barr 2005). Grain growers with limited access to water resources and infrastructure are even more vulnerable given the further reduction of water availability anticipated as a result of climate change and associated impacts on grains quantity, quality and grade (Kokic et al. 2005).

Grain growers in the region are embracing conservation practices such as minimum tillage sowing, windbreaks and soil preservation strategies, to improve their resilience and adaptability. Farmers are also actively involved in various environmental restoration initiatives, such as landcare (e.g. improve landcover and native vegetation), watercare (e.g. water harvesting, improve irrigation management practices, water use efficiency), and field day exhibitions, to promote new practices and exchange ideas (Curtis 2006).

\subsubsection{ENVIRONMENTAL AND INFRASTRUCTURE ADAPTATION: WIMMERA-MALLEE PIPELINE}

There are a range of opportunities available to farmers providing that proactive and effective actions are taken early. For instance, water shortages could be reduced by the Wimmera-Mallee pipeline project providing water for economic and recreational activities. Farmers will benefit from high quality and reliable water and options to develop other opportunities like hydroponics and value-added businesses such as packaging and animal breeding (GWMW 2005). The increased pressure on the scarce water resources in the region suggests, however, that long-term water adaptation strategies should favour improving efficient water management practices which “...may include improved water-shed management, changing crop schedules to use effective rainfall more efficiently, and on- or off-farm water capture, storage and recycling" (Kokic et al. $2005,168)$. It can be anticipated a renewed interest and debate on 'water crisis' such as competition (e.g. urban versus rural/agriculture), allocation, cost, treatment and recycling.

\subsubsection{SOCIO-ECONOMIC ADAPTATIONS}

Entrepreneurs are exploring niche markets within and outside the agriculture sectors. New activities are important strategies for regional revitalisation, especially for livelihood diversification (including off-farm income), employment and population retention. For example, $L u v-a-d u c k$, a business built on duck products established in the 1960s now employs more than 200 people, is one of the important economic activities in the small town of Nhill in the Wimmera. Similarly, there have been some signs of urban rural migration (often referred to as tree change). The impacts 
(both negative and positive) of new rural migrants (welfare recipients, superannuates or retirees) on the local communities and farming, are yet to be fully understood.

Local adaptation strategies should complement long term mitigation such as further reduction of greenhouse gas emissions via the use of cleaner and renewable energies. Laboratory tests suggest that there is a likelihood of enhanced $\mathrm{CO}_{2}$ levels, which could increase wheat yields, but will negatively impact on the quality of the grains (Ugalde and Sanjiva 2006). However, a field study has shown that other climatic stressors (e.g. low rainfall, high temperature, source-sink relationships, pest-crop interactions, and salinity) would gradually offset the potential $\mathrm{CO}_{2}$ benefits (Amthor 2001; Anwar et al. 2006). In that context it is important to identify, stimulate and share good practices which can benefit from changing climate. These include efficient water usage through irrigation (e.g. covered irrigation channels), 'glasshouse' agriculture, opportunistic farming (e.g. market-driven cropping) and high value commodities as responses to declining rainfall, provided that the area has a sufficient groundwater table. One of the findings of the Stern (2006) review on the economics of climate change recognises that the benefits of early adapting and mitigation actions outweigh the economic cost of inaction or late responses.

\subsection{LONG-TERM REGIONAL ADAPTATION STRATEGIES}

The successes and failures of ancient civilizations and indigenous land management practices offer many lessons including how to (or how not to, unfortunately) recognise danger and take appropriate proactive measures (Orlove 2005; Diamond 2005; Wright 2004). Local and shortterm initiatives and opportunities could enhance climate change adaptability. However, successful adaptation strategies could be limited by a range of internal and external factors (multiple exposures) over which industries, community and individuals have less control (Belliveau et al. 2006; Wilbanks 2005) like globalisation, global market responses, consumer preference, policy changes and financial support. For instance, market responses will gradually influence climate change and adaptation strategies. Financial institutions (e.g. insurance and banks) are already adapting their businesses, especially by accounting for climate change and extreme event-related risks (AGO 2005). These internal and external factors will contribute to an array of long-term adaptation strategies, which could be facilitated by Government provision of climate change information, services and assistance in developing place-based responses for the more vulnerable communities.

\subsubsection{GOVERNMENT SUPPORT}

Government could facilitate the longer-term adaptive capacity planning of grain growers via information provision on the likely impacts of climate change. The World Trade Organisation's Doha Development Round negotiations aimed at reducing trade barriers around the world, if successful, could benefit grains growers in the Victorian wheatbelt whose crops are largely exported. Other schemes such as carbon and emission sinking, trading and abatement could become attractive and bring early benefits to institutions and individuals who have taken earlier adaptive actions. Government could choose to intervene to secure effective crop insurances for grain growers, as was the case in Canada (Belliveau et al. 2006). Local and state governments may be lobbied more frequently for permanent exceptional circumstances-type assistance or funds. The Victorian Government is promoting the preparedness of primary producers to deal with adverse seasonal conditions, which are part of doing business in South East Australia, via improved in- 
formation on climate change and blue sky research into relevant new technologies (DSE 2005; AGO 2005).

\subsubsection{TARGETED INFRASTRUCTURE}

Investment in targeted infrastructure is another important long-term adaptation strategy. Transport infrastructure will be under increasing pressure to respond to changing activities, landscapes and lifestyle. For instance, Horsham airport may need upgrading to address the issue of remoteness and cost of travel (fuel price) as identified by the stakeholders during the interviews and at the workshops.

Some adaptation strategies could have negative implications on other sectors and increase their vulnerability and risk. For instance, moving wheat production from a less suitable area to a more suitable one could be more costly, particularly in relation to finding adequate infrastructure and services (storage facilities, transport facilities, processing facilities, irrigation schemes and skills). In the meantime, it will be difficult and costly to move established infrastructure where grains are currently produced, especially in a rapid climate change scenario. Additionally, grains growers and industries could be reluctant to invest in long-term localised infrastructure if the climate suitability continues to compromise farm viability.

\subsubsection{TECHNOLOGY, RESEARCH AND DEVELOPMENT}

A greater emphasis on science and technology was also suggested by the stakeholders. This trust in science and technology was further reflected in the possible adaptive responses to declines in rainfall, yield and productivity. In this context, research will have a pivotal role, particularly in crop breeding. Farmers and industry groups are seeking crop breeding research to continue to develop new varieties and species resistant to drought, dust, wind, salinity, heat, low water-intensive and heat-tolerant. There is a strong interest from growers to seek alternative crops with good market prospects. Under the current gradual decrease in grains suitability, these technologydriven responses could not only be costly, but also bound by productivity threshold which will ultimately compromise their viability.

Technology, research and development could contribute to a range of short-term adaptation strategies to increase the resilience of grains to climate change. One such adaptation strategy includes the development of plant species more suited to changing regional conditions: increasing soil fertility and resistance to pest and diseases, reducing moisture stress and minimising sensitivity to frost, extreme heat, and variation in crop timing. The Grains Research and Development Corporation and the Victorian Department of Primary Industries are examples of agricultural peak bodies currently providing knowledge and expertise in that area. Science may also provide solutions to the eroding terms of trade and climatic constraints. Such innovation could be in the fields of biotechnology, biofuel and nanotechnology. Meanwhile innovative farmers could continue to diversify their crops and income sources, apply selective herbicides for weed and pest control or increase their farm size (DSRD and DNRE 2001; Anwar et al. 2006). It is predicted that the reduction in wheat yield will lead to more farmers diversifying production and source of income or moving into less risky alternatives (Kokic et al. 2005). Technology innovations include investment in efficient machinery, improved information and communication strategies, and enhanced farm management practices (e.g. weather forecast, market and consumer preferences and crop timing). Small scale farmers with less disposable incomes often have low technology 
investment and uptake, and thus are more vulnerable to being squeezed out of business (Anderson 1993).

\section{CONCLUSIONS}

This research has shown the importance of targeting information to specific industries, like the grains industry and local communities in the wheatbelt of north-western Victoria. This acknowledges the important spatial variation in adaptive capacity and the subsequent policy implications.

Three key lessons can be drawn from this study.

1. Firstly, indicators of adaptive capacity and associated indexes should be developed in collaboration with the relevant stakeholder groups. The choice of participant, the level of participation and involvement in the process is important in validating and facilitating the decision-making process and developing a sense of ownership in the output. However, it was noted that participants are generally well aware of climate issues and are willing to take proactive measures, particularly when potential opportunities were highlighted. Further work could explore and explain the consistency and variation amongst ACI indicator sets as well as examine the relationship between groups involved in the project. For example, it could be valuable to explore other methods such as principal components analysis, Analytic Hierarchy Process, bayesian probability and factor analysis to derive weightings and statistical scores. Scores obtained from such methods could then be compared against the scores of stakeholders.

2. The second lesson relates to the way climate change information is presented and communicated. This study shows that climate change issues must be framed within the context of structural and global change, including the wider local and regional implications. Moreover, using GIS to develop and spatially represent the variation proved to be an effective communication tool.

3. Finally, it was observed that stakeholders' inputs were important to identify the areas where they could respond most effectively. In doing so, it was vital to legitimise the insights of stakeholders and experience and validate their outputs. More importantly, it enabled for participants to identify areas where they can best act to improve communities and industry resilience to climate change.

\section{ACKNOWLEDGEMENTS}

The adaptive capacity research is an integral component of the broader study entitled "Facing the Challenge of Climate Change - Impacts and Adaptation in Regional and Agricultural Systems in Victoria" carried out by Primary Industries Research Victoria (PIRVic), as part of the project Climate Change Challenge for Victorian Agricultural Systems. The project is funded by the following institutions: Agricultural Development Division and the Strategic Policy Division (SPD) of the Victorian Department of Primary Industries (DPI); the Greenhouse Policy Unit (GPU) of the Victorian Department of Sustainability and Environment (DSE); and the Australian Greenhouse Office (AGO) of the Commonwealth Department of the Environment and Heritage. I would like to thank participants to the interviews and stakeholder engagement workshops for their contribution. I am also grateful to my colleagues at PIRVic for their support and useful feedback. I am 
grateful to Mr David Griffin of Strategic Policy Group at DPI for his useful comments. Dr Neil Barr (DPI) and Ms Fiona McKenzie (DSE) are also thanked for their assistance in providing data for indicators development.

\section{REFERENCES}

ABS (Australian Bureau of Statistics). 2005. Integrated regional database, Catalogue 1353.0. Canberra. Adger, W. Neil. 2003. 'Social capital, collective action and adaptation to climate change'. Economic Geography 79: 387-404.

Adger, W. Neil, Saleemul Huq, Jouni Paavola, and MJ Mace, eds. 2006. Fairness in Adaptation to climate change: Massachusetts Institute of Technology Press.

AGO (Australian Greenhouse Office). 2005. Climate change risk and vulnerability: Promoting an efficient adaptation response in Australia. Canberra: Department of the Environment and Heritage.

Agrawal, A. 2002. Common resources and institutional sustainability. In The drama of the commons, edited by E. Ostrom, T. Dietz, N. Dolsak, P. C. Stern, S. Stonich and E. U. Weber: National Academy Press.

Agriculture Victoria Services. 2002. Land suitability mapping: Commodities models-Criteria for growth. Melbourne.

Alberini, Anna; Chiabai, Aline; Muehlenbachs, Lucija. 2006. 'Using expert judgement to assess adaptive capacity to climate change: evidence from a conjoint choice survey'. Global Environmental Change 16: 123-144.

Allen, J. C.; Voght, R.; Ko, S. 2001. 'Relationships between community attributes and residential preference in non-metropolitan Nebraska'. Great Plains Research 11 (2): 327-346.

Allison, Edward H., W. Neil Adger, Marie-Caroline Badjeck, Katrina Brown, Declan Conway, Nick K. Dulvy, Ashley Halls, Allison Perry, and John D. Reynolds. 2005. Fisheries Management Science Programme Department for International Development.

Amthor, Jeffrey S. 2001. 'Effects of atmospheric $\mathrm{CO}_{2}$ concentration on wheat yield: review of results from experiments using various approaches to control $\mathrm{CO}_{2}$ concentration'. Field Crops Research 73: $1-34$.

Anderson, J. R. 1993. 'The economics of new technology adaptation and adoption'. Review of Marketing and Agricultural Economics 61 (2): 301-109.

Anwar, Muhuddin, Garry O'Leary, David McNeil, Hemayet Hossain and Roger Nelson. 2006. Climate change impact on field crops and adaptation options in Southeastern Australia, Proceedings of the $13^{\text {th }}$ Australian Society of Agronomy, Perth, 10-14 Sep. 2006.

Bhadwal, Suruchi, Preety Bhandari, Akram Javed, Ulka Kelkar, Karen O'Brien, and Stephan Barg. 2003. Coping with global change: Vulnerability and adaptation in Indian agriculture. New Dehli: The Energy and Resources Institute.

Barr, Neil. 2005. Understanding Rural Victoria. Bendigo: Department of Primary Industries.

del Barrio, G.; Harrison, P. A.; Berry, P. M.; Butt, N.; Sanjuan, M. E.; Pearson, R. G.; Dawson, T. 2006. 'Integrating multiple modelling approaches to predict the potential impacts of climate change on species' distributions in contrasting regions: comparison and implications for policy'. Environmental Sciences and Policy 9: 129-147.

Becken, Susanne. 2005. 'Harmonising climate change adaptation and mitigation: The case of tourist resorts in Fiji'. Global Environmental Change 15: 381-393

Belliveau, Suzanne, Barry Smit, and Ben Bradshaw. 2006. Multiple exposures and dynamic vulnerability: Evidence from grape industry in the Okanagan Valley, Canada. Global Environmental Change (Forthcoming).

Berry, P. M.; Rounsevell, M. D. A.; Harrison, P. A.; Audsley, E. 2006. change and the role of policy in facilitating adaptation'. Environmental Sciences and Policy 9: 189-204. 
Brooks, N.; Adger, W. N.; Kelly, P. M. 2005. 'The determinants of vulnerability and adaptive capacity at the national level and the implications for adaptation'. Global Environmental Change 15: 151-163.

Bureau of Rural Sciences. 2006. Climate change. Adaptation in Agriculture. In Sciences for Decision Makers. Canberra: Bureau of Rural Sciences, Department of Agriculture, Fisheries and Forestry.

Curtis, Allan. 2006. Landcare in Victoria: after twenty years. Canberra: Australian Government Department of Agriculture, Fisheries and Forestry.

Curtis, Allan, and Ian Byron. 2002. Understanding the social drivers of catchment management in the Wimmera region. Albury: Department of Natural Resources and Environment and Wimmera Catchment Management Authority.

Department of State and Regional Development (DSRD), and Department of Natural Resources and Environment (DNRE). 2001. Niche rural industries. Export opportunities for Victoria, Joint background report to the Economic Development Committee of Victoria Parliament. Melbourne.

Diamond, Jared. 2005. Collapse: How societies choose to fail or survive. London: Penguin Group.

DSE (Department of Sustainability and Environment). 2005. Our Environment Our Future. The Victorian Government of Sustainability and Environment. Melbourne.

DVC (Department of Victorian Community). 2005. Indicators of community strength at the local government area level in Victoria. Melbourne: Strategic Policy and Research, Department of Victorian Community.

Ford, James D.; Smit, Barry; Wandel, Johanna. 2006. 'Vulnerability to climate change in the Arctic: A case study from Arctic Bay, Canada'. Global Environmental Change 16: 145-160.

Giupponi, Carlo; Ramanzin, Maurizio; Sturaro, Enrico; Fuser, Simonetta. 2006. 'Climate and land use changes, biodiversity and agri-environmental measures in Bulluno province, Italy'. Environmental Sciences and Policy 9: 163-173.

Grothmann, Torsten; Patt, Anthony. 2005. 'Adaptation capacity of human cognition: The process of individual adaptation to climate change'. Global Environmental Change 15: 199-213.

GWMW (Grampians Wimmera Mallee Water). 2005. Grampians Wimmera Mallee Water Annual Report 2004-2005. Sourced 06/04/06: http://www.wmwater.org.au.

Harrison, P. A.; Berry, P. M.; Butt, N.; New, M. 2006. 'Modelling climate change impacts on species' distributions at European scale: implications for conservation policy'. Environmental Sciences and Policy 9: 116-128.

Harrison, S.; Qureshi, M. E. 2000. 'Choice of stakeholder groups and members in Multicriteria decision models'. Natural Resources Forum 24: 11-19.

Hobbs, B. F. 1997. 'Bayesian methods for analysing climate change and water resource uncertainties'. 49 (1): 53-72.

Howden, S M, and S Crimp. 2005. Assessing dangerous climate change impacts on Australia's wheat industry. Paper read at MODSIM 2005 International Congress on Modelling and Simulation.

Innes, J. 1994. Knowledge and public policy: the search for meaningful indicators. 2nd ed. New Brunswick: Transaction Publishers.

IPCC (Intergovernmental Panel on Climate Change). 2001. Technical summary - Climate Change 2001: Impacts, adaptation and vulnerability - A report of Working Group II. Cambridge: Cambridge University Press.

Joyeeta, Gupta. 2001. On Behalf on my delegation: A survival guide for developing country climate change negotiators. Washington DC: Center for Sustainable Development of the Americas and the International Institute for Sustainable Development.

Karl, Thomas R.; Knight, Richard W.; Easterling, David R.; Quayle, Robert G. 1996. 'Indices of climate change for the United States'. Bulletin of the American Meteorological Society 77 (2): 279-292.

Klein, Richard J. T.; Lisa, E.; Schipper, F.; Dessa, Suraje. 2005. 'Integrating mitigation and adaptation into climate change and development policy: three research questions'. Environmental Sciences and Policy 8: 579-588.

Kokic, Phil; Heaney, Anna; Pechey, Lili; Crimp, Steve; Fisher, Brian S. 2005. 'Climate change. Predicting the impacts on agriculture: A case study'. Australian commodities 12 (1): 161-170. 
Kundzewicz, Zbigniew W;; Budhakooncharoen, Saisunee; Bronstert, Axel; Hoff, Holger; Lettenmaier, Dennis; Menzel, Lucas; Schulze, Roland. 2002. 'Coping with variability and change: Floods and droughts'. Natural Resources Forum 26: 263-274.

Lazo, Jeffrey K; Kinnell, Jason C; Fisher, Ann. 2000. 'Expert and layperson perceptions of ecosystem Risk'. Risk Analysis 20 (2): 179-193.

Ludwid, F., and S. Asseng. 2005. Impacts and Adaptation to Climate Change in Western Australian Wheat Cropping Systems. Paper read at MODSIM 2005 International Congress on Modelling and Simulation, December 2005.

Martin, Peter; King, Jo-Anne; Puangsumalee, Phantipa; Tulloh, Catherine; Treadwell, Rhonda. 2005. 'Australian farm survey results'. Australian commodities 12 (1): 180-199.

Metzger, Marc J. 2005. European vulnerability to global change: a spatial explicit and quantitative assessment. $\mathrm{PhD}$, van Wageningen Universiteit The Netherlands, Wageningen.

Naess, Lars Otto; Norland, Ingrid Thorsen; Lafferty, William M.; Aall, Carlo. 2006. 'Data and process linking vulnerability assessment to adaptation decision-making on climate change in Norway'. Global Environmental Change 16: 221-233.

Nelson, Rohan; Kokic, Phil; Elliston, Lisa; King, Jo-Anne. 2005. 'Structural adjustment. A vulnerability index for Australian broadacre agriculture'. Australian commodities 12 (1): 171-179.

O'Brien, Karen; Leichenko, Robin. 2003. 'Winners and Losers in the Context of Global Change'. Annals of the Association of American Geographers 93 (1): 99-113.

O’Brien, Karen; Leichenko, Robin; Kelkar, Ulka; Venema, Henry; Aandahl, Guro; Tompkins, Heather; Javed, Akram; Bhadwal, Suruchi; Barg, Stephan; Nygaard, Lynn; West, Jennifer. 2004. 'Mapping Vulnerability to Multiple Stressors: Climate Change and Economic Globalization in India'. Global Environmental Change 14 (4): 303-313.

O’Connor, Robert E.; Bord, Richard J.; Fisher, Ann. 1999. 'Risk perceptions, general environmental beliefs, and willingness to address climate change'. 19 (3): 461-471.

Orlove, Ben. 2005. 'Human adaptation to climate change: A review of three historical cases and some general perspectives'. Environmental Sciences 8: 589-600.

Paavola, Jouni; Adger, W. Neil. 2006. 'Fair adaptation to climate change'. Ecological Economics 56: 594-609

Penm, Jammie; Gleeson, Trish; Barrett, David; Connell, Peter; Ashton, Dale; Martin, Peter; Sheales, Terry. 2003. '2002-2003 drought: Review of its impact on Australian agriculture'. Australian commodities 10 (3): 390-395.

Pielke, Roger A., Jr. 2005. 'Misdefining "climate change”: Consequences for science and action'. Environmental Sciences and Policy 8: 548-561

Reid, Paul; Vogel, Coleen. 2006. 'Living and responding to multiple stressors in South Africa: Glimpses from KwaZulu-Natal'. Global Environmental Change 16: 195-206.

Rounsevell, M. D. A.; Berry, P. M.; Harrison, P. A. 2006. 'Future environmental change impacts on rural land use and biodiversity: a synthesis of the ACCELERATES project'. Environmental Sciences and Policy 9: 93-100.

Saaty, T.; Vargas, L. 2001. Models, Methods, concepts and Applications of the Analytic Hierarchy Process. Kluwer Academic Publishers, Norwell, Massachusetts.

Schellnhuber, Hans Joachim, Wolfgang Cramer, Nebojsa Nakicenovic, Tom Wigley, and Gary Yole, eds. 2006. Avoiding dangerous climate change. Cambridge: Cambridge University Press.

Sposito, Victor, Patricia Fitzsimons, Carys Evans, and Hemayet Hossain. 2005a. Adaptation to climate change and adaptive capacity in agriculture systems: Literature review. Melbourne: Department of Primary Industries.

Sposito, Victor, Hemayet Hossain, Dale Watson, and Deanne Barnes. 2005b. Climate change adaptation in Victoria-Agricultural risk assessment. Melbourne: Department of Primary Industries.

Stehr, Nico. 2005. 'Introduction to papers on mitigation and adaptation strategies for climate change: protecting nature from society or protecting society from nature?' Environmental Sciences and Policy 8: 537-540. 
Stern, N. 2006. The economics of climate change: The Stern review. Cabinet Office - HM Treasury and Cambridge University Press, Cambridge (www.stermreview.org.uk).

The Economist. 2003. 'Hot potato revisited'. 6th November.

Tol, Richard S. J. 2005. 'Adaptation and mitigation: trade-offs in substance and methods'. Environmental Sciences and Policy 8: 572-578.

Tompkins, Emma L.; Adger, W. Neil. 2005. 'Defining response capacity to enhance climate change policy'. Environmental Sciences and Policy 8: 562-571.

Ugalde, David; Sanjiva, De Silva. 2006. 'Considering the impact of climate change on the quality of Australian wheat'. Proceedings of Australasian Milling Conference, Surfers Paradise; 43-52.

VCMC (The Victorian Catchment Management Council). 2002. 'The health of our catchments: A Victorian report card 2002'. Melbourne: The Victorian Catchment Management Council.

Welp, Martin; de la Vega-Leinert, Anne; Stoll-Kleemann, Susanne; Jaeger, Carlo C. 2006. 'Science-based stakeholder dialogues: Theories and tools'. Global Environmental Change 16: 170-181.

Wilbanks, Thomas J. 2005. 'Issues in developing a capacity for integrated analysis of mitigation and adaptation'. Environmental Sciences and Policy 8: 541-547.

Wright, Ronald. 2004. A short history of progress. Toronto: House of Anasi Press Inc.

Yamin, Farhana; Rahman, Atiq; Huq, Saleemul. 2005. 'Vulnerability, adaptation and climate disasters: A conceptual overview'. Institute of Development Studies (IDS) Bulletin 36 (4): 1-14.

Cite this article as: Sietchiping, Remy. 2007. 'Applying an index of adaptive capacity to climate change in north-western Victoria, Australia'. Applied GIS 2 (3): pp. 16.1-16.28. DOI: 10.2104/ag060016. 